\title{
Sub-Optimal Breastfeeding and Its Associated Factors in Rural Communities of Hula District, Southern Ethiopia: A Cross-Sectional Study
}

\author{
Shibru Hoche ${ }^{1}$, Berhan Meshesha ${ }^{2}$, Negash Wakgari ${ }^{3 *}$
}

\footnotetext{
OPEN ACCESS

Citation: Shibru Hoche, Berhan Meshesha, Negash Wakgari. SubOptimal Breast Feeding and Its

Associated Factors in Rural Communities of Hula District, Southern Ethiopia: A Cross-Sectional Study. Ethiop J Health Sci.2017;28(1):49.

doi:http://dx.doi.org/10.4314/ejhs.v28i1. 7

Received: July 20, 2017

Accepted: July 20, 2017

Published: January 1, 2018

Copyright: (C) 2018 Shibru Oche, et al This is an open access article distributed under the terms of the Creative Commons Attribution L icense, which permits unrestricted use, distribution, and reproduction in any medium, provided the original author and source are credited.

Funding: Nil

Competing Interests: The authors declare that this manuscript was approved by all authors in its form and that no competing interest exists. Affiliation and Correspondence:

${ }^{1}$ Yirba Primary Hospital, Sidama

Zone, Ethiopia

${ }^{2}$ College of Medicine and Health

Science, Hawassa University,

Hawassa, Ethiopia

${ }^{3}$ School of Nursing and Midwifery,

College of Medicine and Health

Sciences, Hawassa University,

Hawassa, Ethiopia

*Email: negashwakgari@yahoo.com
}

\begin{abstract}
BACKGROUND: Sub-optimal breast feeding contributed a significant number of infants' death. Although breast feeding is universal in Ethiopia, the practice is not optimal. Hence, this study assessed the prevalence of sub-optimal breast feeding practice and its associated factors in rural communities of Hula District, Southern Ethiopia.

METHODS: A community based cross-sectional study was conducted among 634 women with infants aged 6 to 12 months. Multistage sampling technique was employed to select study subjects. Interviewer administered structured questionnaire was used for data collection. Data were entered and analyzed by using SPSS version 20.0. Bivariate and multivariate logistic regression was used to identify predictors of delayed initiation of breastfeeding and non-exclusive breastfeeding.

RESULTS: The prevalence of suboptimal breast feeding of infants was found to be $56.9 \%$. Nearly half (49.4\%) of the mothers delayed initiation of breast feeding, and $13.4 \%$ of the infants were fed breast non-exclusively. Having formal education [AOR: 1.74; 95\% CI (1.17, 2.59)], family size < 5 [AOR=1.59; 95\% CI (1.03, 2.45)], having one under five child [AOR=1.88; 95\% CI (1.29, 2.75)], lower number of antenatal care visits [AOR $=2.40 ; 95 \% \mathrm{CI}$ $(1.68,3.43)]$ and lack of counseling on breastfeeding [AOR=1.69; 95\% CI (1.19, 2.41)] were negatively associated with delayed initiation of breast feeding. Similarly, not attending formal education, low birth order and lack of knowledge about exclusive breastfeeding were also negatively associated with exclusive breastfeeding practice.

CONCLUSION: In this study, sub-optimal breast feeding was found to be high. Delayed initiation and non-exclusive breastfeeding practices were major contributors to sub-optimal breast feeding.

KEYWORDS: Sub-optimal breast feeding, Hula District
\end{abstract}




\section{INTRODUCTION}

Breast feeding provides the most suitable food for the healthy growth and development of infants. It is babies' first immunization and the most effective and inexpensive life-saver (1). Breast milk is easily digestible complete food containing all the required nutrients for the first six months' life of the infants and completely satisfies an infant's nutritional and water needs $(2,3)$. Globally, only $38 \%$ of infants aged 0 to 6 months are exclusively breast fed during the period of 2007-2014, while the global nutrition target is to increase the rate of exclusive breast feeding from $38 \%$ to $50 \%$ by 2025 (3). According to the World Health Organization recommendations of infant and young child feeding, to achieve the optimal growth, development and health, breast feeding should be early initiated within one hour after birth $(2,3)$. Similarly, infants should exclusively breastfed for the first six months and the introduction of nutritionally adequate and safe complementary food should be started at the sixth month together with continued breast feeding up to two years and beyond $(3,4)$.

To improve infant and child health, optimal breast feeding is the first priority and highly cost effective preventive intervention (1-3). Every year, optimal breast feeding has the potential of preventing 1.4 million deaths of less than fiveyear children and reduce acute respiratory tract infections and diarrheal deaths by $50-95 \%(4,5)$. It increases the effectiveness of immunization, reduces the need for oral rehydration by $50 \%$ and significantly increases intelligence and readiness to learn $(4,5)$. Exclusive breast feeding is the practice of only giving infant breast milk for the first six month (6). Children who are exclusively breastfed for the first six months are 14 times more likely to survive than non-breast fed children (1). Sub-optimal breast feeding practices during the first six months is the most risk factor for the infant and child morbidity and mortality, including poor school performance, reduced productivityand impaired intellectual development (2-4,7). Annually, sub-optimum breastfeeding alone contributed to more than
800,000 child deaths (8). Moreover, nonexclusive breastfeeding alone contributed to 804 , 000 child deaths in 2011(3). In developing countries, only $39 \%$ of children $<6$ months of age are exclusively breast fed and more than half of 20-23 month olds benefit from the practice of continued breastfeeding (2).

Although breastfeeding is universal in Ethiopia, the practice is not optimal. According to the Ethiopian demographic and health survey reports, the prevalence of exclusive breast feeding was $52 \%$, and $27 \%$ of the newborns received prelacteal feedings like plain water, other milk and butter (10). In addition, sub-optimal breastfeeding practice contributed to 70,000 infants' death, which accounted for $24 \%$ of the total annual infant death $(7,10,11)$. Even though, the Federal Ministry of Health has been working to improve the optimal breast feeding practice through providing training and developing implementation guidelines, its practice remained far from global recommendation(4,12). Moreover, most of the studies conducted in different parts of Ethiopia showed that the major components of sub-optimal breast feeding-non-exclusive breast feeding, delay ininitiation of breast feeding and discarding colostrum are being practiced by mothers $(7,12-20-23)$. In addition, providing prelacteal food and avoiding colostrums are more prevalent in Ethiopia $(2,24)$. However, few studies have been conducted to identify the suboptimal breast feeding practices and associated factors in the study area. Hence, this study assessed the prevalence of sub-optimal breast feeding practices and associated factors in rural communities of Hula District, Southern Ethiopia.

\section{MATERIALS AND METHODS}

Study design, setting and population: A community based cross-sectional study was conducted among infants aged 6 to 12 months and living in Hula District from December to January, 2016. Hula District is one of the 21 districts found in Sidama Zone. It is located $97 \mathrm{~km}$ far from Hawassa, the capital city of Southern Nations, Nationalities and Peoples Regional State and

DOI: http://dx.doi.org/10.4314/ejhs.v28i1.7 
Sidama Zone. There were 32 kebeles in the district during the study period. The total population of the district was 167,268 . Among the total population, 156,666 of them were residing in rural areas. Female population was 84,136 , and 38,973 of them in reproductive age group. Infants aged between 6 to 12 months were 3,345. Infants whose mothers had serious health problems during data collection period were excluded from the study.

Sample size and sampling procedure: The sample size was calculated using single population proportion formula by considering the following assumptions: prevalence of sub-optimal breast feeding $(\mathrm{p})=75 \%$ from the previous study conducted in Southwest Ethiopia (19), 95\% confidence level $(\mathrm{z}=1.96), 5 \%$ margin of error $(\mathrm{d}=0.05)$, and design effect $(\mathrm{D}=2)$. Accordingly, $\mathrm{n}=\mathrm{D}\left(\mathrm{z}^{2} \mathrm{p} \quad(1-\mathrm{p}) / \mathrm{d}^{2} ;=2\left(1.96^{2} * 0.75^{*} 0.25\right) / 0.05^{2}\right.$. Hence, the final sample size with $10 \%$ nonresponse rate becomes 634 . Multi-stage sampling technique was used to identify the study units. In primary sampling stage, among the total of 32 kebeles in Hula District, 12 of were randomly selected by using simple random sampling technique. In the secondary stage, households with 6 to 12 month infants were identified by conducting census in the selected kebeles using health promoters. There were a total of 1,399 infants aged 6 to 12 months in the selected kebeles during the study period. Then, the total sample was allocated proportionally to each kebele based on the number of 6 to 12 month infants. Study subjects were drawn from the sampling frame by using systematic random sampling technique. If there were two infants in one household, one infant was selected randomly. A feeding behavior that did not meet recommended standards including delayed initiation of breast feeding, discarding colostrum and non-exclusive breast feedings are considered as sub-optimal breastfeeding practice.

Data collection tools and procedures: Interviewer administered structured questionnaire was adapted from Ethiopian demographic and health survey (9) and other relevant literatures was used for modifications to fit the study context
(8-11, 19-37). The questionnaire was prepared in English and then translated into a local language, Sidamegna, and back to English. Furthermore, the instrument was pre-tested on 32 respondents in a randomly selected kebeles which were not selected for the study. Findings from the pre-test were used to modify the data collection tool. Eight nurses and two BSc health workers from the district health office were used as data collectors and supervisors. Both the data collectors and supervisors were given a two days' training before the actual data collection. Before the actual data collection, a preliminary survey was conducted using health promoters from each kebele to identify households with infants 6 to 12 months. Data on socio-demographic characteristics, maternal health care and breast feeding status of the last child, knowledge on breastfeeding and cultural beliefs regarding infant feeding practice were collected. To assess the prevalence of suboptimal breastfeeding practice, dietary recall method was used.

Data management and analysis: Data was entered and analyzed using the statistical Package for Social Sciences (SPSS), version 20. Univariate analysis was done using frequenciesand percentages. Data were presented in the form of texts, tables and graphs. Bivariate logistic regression was used to identify candidate variables for multivariate logistic regression analysis. Multivariate logistic analysis was used to control possible confounders and identify independent predictors of delayed initiation of breastfeeding after one hour of delivery and nonexclusive breast feeding practices. Those variables with $\mathrm{p}$ value less than or equal to 0.25 on bivariate analysis were included in multivariate logistic regression model. Significance level of $95 \%$ and $\mathrm{p}$ value less than or equal to 0.05 were used to decide the significance of association.

The quality of the data was assured by properly designing and pre-testing the questionnaire. Proper categorization, coding and skipping patterns of questions were used. Training was given for data collectors and supervisors before the actual data collection. After data

DOI: http://dx.doi.org/10.4314/ejhs.v28i1.7 
collection, data from each household were reviewed and checked for completeness, accuracy, clarity and consistency. This was done by the principal investigator and the supervisors daily immediately after the data were collected. Necessary feedbacks were offered to the data collectors in the next morning. Data cleanup and cross checking were done before analysis.

Ethical considerations: Ethical approval was obtained from the Institutional Review Board of the College of Medicine and Health Sciences, Hawassa University. Written permission was obtained from Hula District Administration Office and Hula District Health Office. Each respondent was informed that the study would provide necessary information for policy makers and other concerned bodies. Written informed consent was obtained from each study subject prior to the data collection process. Any participant who was not willing to participate in the study was not forced to participate. Respondents were also informed that all the data obtained from them would be kept confidential by using codes instead of any personal identifiers and that it would be used only for the purpose of the study. During the data collection process, the data collectors informed each study participant about the purpose and anticipated benefits of the research. Study participants were also informed that they had full right to refuse, withdraw or completely reject the study.

\section{RESULTS}

Socio-demographic characteristics of mothers with infants aged 6 to 12 months: A total of 634 mothers of children aged 6 to 12 months were included in the study making a response rate of $100 \%$. Mothers' mean age was 26.6 years $(\mathrm{SD} \pm$ 5.8 ) and ranged from 15 to 45 years. The mean age of infants was 9.7 months $(\mathrm{SD} \pm 2.1)$ and ranged from 6 to 12 months. Nearly half (49.2\%) of the respondents were in the age group of 25-34 years. Most $(97.2 \%)$ of the study participants were Sidama in ethnicity. Regarding marital status of the respondents, $99.1 \%$ were in marital union. Protestant religion was the dominant religion reported by $94 \%$. With regard to educational status, $42.3 \%$ had no formal education, and $47.8 \%$ attended primary education (Table 1).

Table 1: Socio-demographic characteristics of respondents in Hula district, south Ethiopia, 2016.

\begin{tabular}{|c|c|c|}
\hline Variables $(n=634)$ & Frequency & $\%$ \\
\hline \multicolumn{3}{|l|}{ ANC visits } \\
\hline Yes & 601 & 94.8 \\
\hline No & 33 & 5.2 \\
\hline \multicolumn{3}{|l|}{ Number of ANC visit } \\
\hline None & 32 & 5 \\
\hline $1-3$ & 351 & 55.4 \\
\hline$\geq 4$ & 251 & 39.6 \\
\hline \multicolumn{3}{|l|}{ Counseling on } \\
\hline breastfeeding (during & 334 & 52.7 \\
\hline ANC visits) & 300 & 47.3 \\
\hline \multicolumn{3}{|l|}{ Yes } \\
\hline \multicolumn{3}{|l|}{ No } \\
\hline \multicolumn{3}{|l|}{ Place of delivery } \\
\hline Home & 276 & 43.5 \\
\hline Health facility & 358 & 56.5 \\
\hline \multicolumn{3}{|l|}{ Type of delivery } \\
\hline Vaginal delivery & 626 & 98.7 \\
\hline Cesarean section & 8 & 1.3 \\
\hline \multicolumn{3}{|l|}{ Post natal care } \\
\hline Yes & 200 & 31.5 \\
\hline No & 434 & 68.5 \\
\hline \multicolumn{3}{|l|}{ Birth order } \\
\hline First-born & 182 & 28.7 \\
\hline $2-3$ & 199 & 31.4 \\
\hline 4 and more & 253 & 39.9 \\
\hline \multicolumn{3}{|l|}{ Parity } \\
\hline $1-2$ children & 291 & 45.9 \\
\hline 3-4 children & 184 & 29.0 \\
\hline$>4$ children & 159 & 25.1 \\
\hline \multicolumn{3}{|l|}{ Number of under 5} \\
\hline 1 & 223 & 35.2 \\
\hline \multicolumn{3}{|l|}{$\geq 2$} \\
\hline \multicolumn{3}{|l|}{ Sex of the infants } \\
\hline Male & 354 & 55.8 \\
\hline Female & 280 & 44.2 \\
\hline \multicolumn{3}{|l|}{ Age of the infants } \\
\hline 6-9 months & 267 & 42.1 \\
\hline $10-12$ months & 367 & 57.9 \\
\hline
\end{tabular}

DOI: http://dx.doi.org/10.4314/ejhs.v28i1.7 
Characteristics of mothers with infants aged 6

to 12 months: In this study, around ninety five percent $(94.8 \%)$ of $t$ hmothers had at least one antenatal visit. Regarding the number of the Antenatal Care(ANC) visits attended, 251(39.6\%) of mothers attended four times and above. Among those who attended ANC visits, 334 (52.7\%) received counseling about breast feeding practice.
More than half $(56.5 \%)$ of the respondents gave birth at the health facility. Most $(98.7 \%)$ of the mothers delivered spontaneously, and only $1.3 \%$ of them delivered by caesarean secession. This study reported that only $200(31.5 \%)$ of the mothers had postnatal care services. Four hundred eleven $(64.8 \%)$ of the mothers had only one under five year child (Table 2).

Table 2: Maternal and child characteristics in Hula district, Southern Ethiopia, 2016.

\begin{tabular}{|c|c|c|}
\hline Variables $(n=634)$ & Frequency & $\%$ \\
\hline \multicolumn{3}{|l|}{ Maternal age } \\
\hline $15-24$ & 230 & 36.3 \\
\hline $25-34$ & 312 & 49.2 \\
\hline$\geq 35$ & 92 & 14.5 \\
\hline \multicolumn{3}{|l|}{ Religion } \\
\hline Protestant & 596 & 94 \\
\hline Others* & 38 & 6 \\
\hline \multicolumn{3}{|l|}{ Ethnicity } \\
\hline Sidama & 616 & 97.2 \\
\hline Amhara & 12 & 1.9 \\
\hline Others** & 6 & 0.9 \\
\hline \multicolumn{3}{|l|}{ Marital status } \\
\hline Currently in marital union & 628 & 99.1 \\
\hline Currently not in marital union & 6 & 0.9 \\
\hline \multicolumn{3}{|l|}{ Mothers education } \\
\hline Illiterate & 268 & 42.3 \\
\hline Primary school & 303 & 47.8 \\
\hline High school and above & 63 & 9.9 \\
\hline \multicolumn{3}{|l|}{ Husbands education } \\
\hline Illiterate & 158 & 24.9 \\
\hline Primary school & 330 & 52.1 \\
\hline High school and above & 145 & 22.9 \\
\hline \multicolumn{3}{|l|}{ Occupation of mother } \\
\hline Housewife & 607 & 90.7 \\
\hline Others $* * *$ & 27 & 4.3 \\
\hline \multicolumn{3}{|l|}{ Occupation of husbands } \\
\hline Farmer & 463 & 73.3 \\
\hline Others $* * * *$ & 167 & 26.7 \\
\hline \multicolumn{3}{|l|}{ Family Size } \\
\hline$<5$ & 353 & 55.7 \\
\hline$\geq 5$ & 281 & 44.3 \\
\hline \multicolumn{3}{|l|}{ Economic status } \\
\hline$<500 \mathrm{ETB}$ & 217 & 34.2 \\
\hline 500-1000 ЕТВ & 265 & 41.8 \\
\hline $1000-1500$ ЕTВ & 91 & 14.4 \\
\hline$>1500$ ETB & 61 & 9.6 \\
\hline \multicolumn{3}{|l|}{ Ownership of radio } \\
\hline Yes & 96 & 15.1 \\
\hline No & 538 & 84.9 \\
\hline
\end{tabular}

DOI: http://dx.doi.org/10.4314/ejhs.v28i1.7 
Breast feeding practice: In this study, all mothers had ever breastfed and were currently breast feeding their infants. About half, $321(50.6 \%)$, of the mothers initiated breast feeding early within one hour after giving birth, and $609(96.1 \%)$ fed colostrum to their infants. Two hundred seventy two (42.9\%) of the mothers reported that providing plant herbs (locally named as "ameessa") for infants as if it is a culture and important for child health, while $(28.7 \%)$ of them provided "ameessa" for their infants believing that it would prevent infants from diseases, moistens digestive system and is culturally supported Considerable (86.6\%) proportions of mothers fed breast exclusively. Most (87.7\%) of the respondents started feeding complementary foods timely (around six months). In this study, only $(43.1 \%)$ of the mothers fed breast optimally (Table 3).

Maternal knowledge about breast feeding practices: Most, 590(93.1\%), of the study participants were found to have awareness on early initiation of breast feeding within one hour after delivery, and 619(97.6\%) knew the recommended months to start complementary feeding (Table 4).

Table 4: Maternal knowledge about breast feeding in Hula district, 2016.
Table 3: Breastfeeding practice in Hula district, 2016.

\begin{tabular}{lll}
\hline Variables (n=634) & Frequency & $\mathbf{\%}$ \\
\hline Ever breast fed & 634 & 100 \\
Breast feeding initiation & & \\
$\quad$ Within one hour & 321 & 50.6 \\
$\quad$ After one hour & 313 & 49.4 \\
Giving colostrum & & \\
$\quad$ Yes & 609 & 96.1 \\
$\quad$ No & 25 & 3.9 \\
Pre-lacteal feeding & 18 & \\
$\quad$ Yes & 616 & 97.8 \\
$\quad$ No & & \\
Currently breast feeding & 634 & 100 \\
$\quad$ Yes & & \\
Exclusive breast feeding & 549 & 86.6 \\
$\quad$ Yes & 85 & 13.4 \\
$\quad$ No & & \\
Timely complementary feeding & 556 & 87.7 \\
$\quad$ Yes & 78 & 12.3 \\
$\quad$ No & & \\
Breastfeeding frequency (day \\
and night) \\
$\quad \leq 8$ \\
$\quad>8$
\end{tabular}

\begin{tabular}{|c|c|c|}
\hline Characteristics $(n=634)$ & Frequency & $\%$ \\
\hline \multicolumn{3}{|c|}{ Aware about importance of early initiation of breast feeding } \\
\hline Yes & 590 & 93.1 \\
\hline No & 46 & 6.9 \\
\hline \multicolumn{3}{|c|}{ Aware about importance of feeding colostrum. } \\
\hline Yes & 611 & 96.4 \\
\hline No & 23 & 3.6 \\
\hline \multicolumn{3}{|c|}{ Aware about importance of exclusive breast feeding. } \\
\hline Yes & 610 & 96.2 \\
\hline No & 24 & 3.8 \\
\hline \multicolumn{3}{|c|}{ Aware about continuity of breast feeding for 2 years and above } \\
\hline Yes & 601 & 94.8 \\
\hline No & 33 & 5.2 \\
\hline \multicolumn{3}{|c|}{ Know when to start complementary feeding } \\
\hline Yes & 619 & 97.6 \\
\hline No & 25 & 2.4 \\
\hline
\end{tabular}

DOI: http://dx.doi.org/10.4314/ejhs.v28i1.7 
Factors associated with delayed initiation of breast feeding: On bivariate logistic regression, age of mothers, women educational status, family size, number of under five year children, number of antenatal care visits, counseling on breastfeeding during antenatal care visits, discarding colostrum and having radio were found children, number of antenatal care visits, counseling on breast feeding during antenatal care visits and discarding colostrum were found to be significant predictors of delayed initiation of breastfeeding.

Mothers who had no formal education were nearly two times more likely to delay initiation of breastfeeding than those who had formal education [AOR: 1.74; 95\% CI $(1.17,2.59)$ ]. Furthermore, mothers who had family size of $<5$ were found to be more likely to delay initiation of breastfeeding than those with family size $\geq 5$ $[\mathrm{AOR}=1.59 ; 95 \%$ CI $(1.03,2.45)]$. Mothers who to have statistically significant association independently with delayed initiation of breastfeeding. However, after controlling for possible confounders on multilogistic regression analysis, age of mothers, women educational status, family size, number of under five year

had one under five year child were nearly two times more likely to delay initiation of breastfeeding than those with two and more children [AOR $=1.88 ; 95 \%$ CI $(1.29,2.75)]$.

Moreover, women who had attended less than four ANC visits were two times more likely to delay early initiation of breastfeeding than those who had four and more visits $[\mathrm{AOR}=2.40 ; 95 \%$ CI $(1.68,3.43)]$. Besides, the women who were not counseled on breastfeeding during ANC visit were more likely to delay early initiation of breastfeeding than those who were counseled $[\mathrm{AOR}=1.69 ; 95 \% \mathrm{CI}(1.19,2.41)]($ Table 5$)$.

Table 5: Factors associated with delayed initiation of breastfeeding among mothers of infants aged 6 months to 1 year in Hula district, south Ethiopia, 2016.

\begin{tabular}{|c|c|c|c|c|c|}
\hline \multirow[t]{2}{*}{ Variables $(n=634)$} & \multicolumn{2}{|c|}{ Delayed initiation of $\mathrm{BF}$} & \multicolumn{2}{|c|}{ OR (95\% CI) } & \multirow[t]{2}{*}{ P-value } \\
\hline & Yes & No & $\operatorname{COR}(95 \% \mathrm{CI})$ & $\operatorname{AOR}(95 \% C I)$ & \\
\hline \multicolumn{6}{|l|}{ Age of mothers } \\
\hline $15-24$ & 113 & 117 & $0.62(0.38,1.01)$ & $0.52(0.27,1.00)$ & \\
\hline 25-34 & 144 & 168 & $0.55(0.34,0.88)$ & $0.61(0.35,1.05)$ & \\
\hline$\geq 35$ & 56 & 36 & 1 & 1 & \\
\hline \multicolumn{6}{|l|}{ Mothers education } \\
\hline Illiterate & 148 & 140 & $1.28(1.10,2.08)$ & $1.74(1.17,2.59)$ & $<0.01$ \\
\hline Literate & 165 & 201 & 1 & 1 & \\
\hline \multicolumn{6}{|l|}{ Number of family } \\
\hline$<5$ & 188 & 165 & $1.42(1.03,1.94)$ & $1.59(1.03,2.45)$ & $<0.05$ \\
\hline$\geq 5$ & 125 & 156 & 1 & 1 & \\
\hline \multicolumn{6}{|c|}{ Number of $<5$ year children } \\
\hline 1 & 228 & 183 & $2.02(1.45,2.82)$ & $1.88(1.29,2.75)$ & $<0.01$ \\
\hline$\geq 2$ & 85 & 138 & 1 & 1 & \\
\hline \multicolumn{6}{|l|}{ Having radio } \\
\hline No & 277 & 261 & $1.76(1.13,2.76)$ & $1.21(0.74,1.96) *$ & \\
\hline Yes & 36 & 60 & 1 & 1 & \\
\hline \multicolumn{6}{|c|}{ Number of antenatal care } \\
\hline None & 15 & 17 & $1.72(0.82,3.61)$ & $1.30(0.59,2.90)$ & \\
\hline $1-3$ & 213 & 138 & $3.01(2.15,4.22)$ & $2.40(1.68,3.43)$ & $<0.01$ \\
\hline$\geq 4$ & 85 & 166 & 1 & 1 & \\
\hline \multicolumn{5}{|c|}{ Breast feeding counseling } & $<0.01$ \\
\hline No & 178 & 122 & 1 & 1 & \\
\hline Yes & 135 & 199 & & & \\
\hline
\end{tabular}

DOI: http://dx.doi.org/10.4314/ejhs.v28i1.7 
Factors associated with non exclusive breast feeding: In bivariate logistic regression analysis, mothers' education, breast feeding counseling during ANC visits, discarding colostrum, birth order and knowledge of exclusive breast feeding were independently found to have statistically significant association with non-exclusive breast feeding of infants. After controlling for confounders with multivariate logistic regression analysis, no mothers' education, no counseling on breast feeding during ANC visits, lower birth order, and having no knowledge of exclusive breast feeding were statistically significantly associated with non-exclusive breast feeding.

Women who had no formal education were nearly two times more likely to feed breast non- exclusively than women who had formal education $[\mathrm{AOR}=1.75 ; 95 \% \mathrm{CI}(1.01,3.03)]$. In addition, mothers who were not counseled on breast feeding during ANC visits were more likely to feed breast non-exclusively than those who were counseled [AOR $=1.67 ; 95 \%$ CI (1.04, 2.70)]. Moreover, women who gave birth for the first time were two times more likely to feed breast non-exclusively than mothers of higher birth order [AOR $=2.05 ; 95 \%$ CI $(1.05,3.97)$ ]. Similarly, women who were knowledgeable about exclusive breast feeding were five times more likely to feed breast exclusively than those who were not knowledgeable $[\mathrm{AOR}=5.10 ; 95 \%$ CI $(2.13,12.24)]$ (Table 6).

Table 6: Selected characteristics associated with non-exclusive breast feeding among mothers of infants aged 6 months to1 year in Hula district, south Ethiopia, 2016.

\begin{tabular}{|c|c|c|c|c|c|}
\hline \multirow[t]{3}{*}{ Variables $(n=634)$} & \multirow{2}{*}{\multicolumn{2}{|c|}{$\begin{array}{l}\text { Non-exclusive } \\
\text { breast feeding }\end{array}$}} & \multicolumn{2}{|c|}{ OR $(95 \%$ CI $)$} & \multirow{3}{*}{ P-value } \\
\hline & & & \multirow[t]{2}{*}{$\operatorname{COR}(95 \% \mathrm{CI})$} & \multirow[t]{2}{*}{$\operatorname{AOR}(95 \% C I)$} & \\
\hline & Yes & No & & & \\
\hline \multicolumn{6}{|l|}{ Mothers education } \\
\hline Illiterate & 41 & 227 & $1.32(0.83,2.07)$ & $1.75(1.01,3.03)$ & $<0.05$ \\
\hline Literate & 44 & 322 & 1 & 1 & \\
\hline \multicolumn{6}{|c|}{$\begin{array}{l}\text { Breast feeding counseling } \\
\text { during antenatal care }\end{array}$} \\
\hline No & 51 & 249 & $1.80(1.13,2.87)$ & $1.67(1.04,2.70)$ & $<0.05$ \\
\hline Yes & 34 & 300 & 1 & 1 & \\
\hline \multicolumn{6}{|l|}{ Postnatal counseling } \\
\hline No & 66 & 368 & $1.70(0.99,2.93)$ & $1.67(0.96,2.91)^{*}$ & \\
\hline Yes & 19 & 181 & 1 & 1 & \\
\hline \multicolumn{6}{|l|}{ Birth order } \\
\hline First and second & 47 & 247 & $1.51(0.91,2.76)$ & $2.05(1.05,3.97)$ & $<0.05$ \\
\hline Third and more & 38 & 302 & 1 & 1 & \\
\hline \multicolumn{6}{|l|}{ Knowledge of EBF } \\
\hline No & 10 & 14 & $5.09(2.18,11.88)$ & $5.10(2.13,12.24)$ & $<0.01$ \\
\hline Yes & 75 & 535 & 1 & 1 & \\
\hline \multicolumn{6}{|c|}{ Discarded colostrums } \\
\hline Yes & 6 & 19 & $2.11(0.82,5.46)$ & $1.58(0.58,4.25)^{*}$ & \\
\hline No & 79 & 530 & 1 & 1 & \\
\hline
\end{tabular}

*= Not significant in backward stepwise logistic regression

DOI: http://dx.doi.org/10.4314/ejhs.v28i1.7 


\section{DISCUSSION}

This study assessed the prevalence of sub-optimal breastfeeding practice and its associated factors among infants during the first six months in rural communities of Hula District, Southern Ethiopia. The prevalence of sub-optimal breast feeding in this study was $56.9 \%$ (CI: 52.4-60.2). Among those who fed breast sub-optimally, $(49.4 \%)$ of them, delayed initiation of breast feeding, (13.4\%) fed breast non-exclusively and (3.9\%) discarded colostrum. This finding is lower than the study conducted in Jimma, Arjo District (75.4\%) (19). This might be due to the difference in the context (socio-cultural difference) and the implementation of the maternal and child health programs. The prevalence of sub-optimal breast feeding in the study area remains high mainly due to cultural beliefs associated with providing "amessa" to newborns and infants. "Amessa" was believed to have importance in preventing diseases, avoiding dryness of digestive system, and supporting growth of the infant.

Similarly, the prevalence of delayed initiation of breast feeding (after the first hour of birth) was found to be (49.4\%) (CI: 46.8 - 52.3). This finding is consistent with the 2011 Ethiopian Demographic and Health Survey (EDHS) report (48\%) (9), Jimma, Arjo District (37\%) (19), Goba Woreda (47.6\%) (13), Enagu, Nigeria (47\%) (38) and $(50 \%)$ in Africa (31). This finding is higher than the finding of the study conducted in the rural part of Ethiopia (41.1\%) (14), Debre Berhan (17.5\%) (18), Bishoftu (28.2\%) (25) and Arbaminch Zuria (42.8\%) (39). However, it is lower than the findings of the studies conducted in Nigeria (62\%), (53.9\%) (11,38), and Pakistan (72.7\%) (39). According to EDHS reports, the prevalence of delayed initiation of breastfeeding was increased from (31\%) to (48\%) between 2005 and 2011(9,41). This implies that early initiation of breastfeeding did not show significant improvement despite the efforts to improve child health. The possible explanations for this difference could be difference in sociodemographic characteristics of the respondents and the place where the study was conducted.
This study showed that delayed initiation of breastfeeding was more likely among mothers who did not attend formal education than mothers who attended formal education. This finding is similar with the finding of the studies conducted in Jimma, Arjo District (19) and Nigeria (11). Moreover, another study conducted in Goba District, Southeast Ethiopia, also showed that mothers who had formal education more initiated breastfeeding within the first hours after delivery (13). This might be related to the fact that mothers who attended formal education were more informed about timely initiation of breastfeeding.

In addition, mothers who had one under five year child were more likely to delaye initiation of breastfeeding than mothers who had more than two under five year children. This finding is consistent with the study done in Nigeria (11). The possible explanation for this finding is that mothers with two or more under five year children had more experience of breast feeding practice.

Moreover, mothers who attended ANC visit $\leq 3$ times were found to be more delaying initiation of breastfeeding compared with mothers who had four and more ANC visits. This finding had agreement with the study conducted in Nigeria in which frequent ANC visit was associated with early initiation of breast feeding (11). However, this finding is inconsistent with the finding of a study conducted ina rural part of Ethiopia in which delayed breast feeding initiation was not affected by the number of ANC visits (14). This inconsistency could be due to the difference in the sample size and study setting.

Mothers who were not counseled about breastfeeding during ANC visits were more likely to delay initiation of breast feeding. This finding is similar with findings of studies conducted in a rural part of Ethiopia (14) and a literature review of the factors that influence breast feeding (42). This might be due to the fact that mothers did not receive breast feeding counseling at the appropriate time and were not aware of when to initiate breast feeding.

Non-exclusive breast feeding practice was found to be $13.4 \%$ (CI: 11.6-15.4) among mothers having infants aged 6 to 12 months. This finding is lower than the findings of studies conducted in

DOI: http://dx.doi.org/10.4314/ejhs.v28i1.7 
East Ethiopia (28.3\%) (43), Enderta Woreda (29.8\%) (16), Debre Markos (39.2\%) (44), Gondar Town (47.5\%) (10), EDHS, 2011 (48\%) (9), Debre Berhan (49.8\%) (18), Arbaminch Zuria (44.4\%) (39), Bishoftu (65.9\%) (25), Ethiopia (51\%) (45), Nigeria (86\%) (11), Mecha District (52.9\%) (7), Enagu, Nigeria (65.5\%) (38), Pakistan (62.9\%) (40) and developing countries (61\%) (46). This might be due to the higher knowledge of exclusive breast feeding practice $(96.2 \%)$ in the study area. Moreover, in the study area, there is a non-governmental organization which is working on a program called 'alive and thrives' and highly promoting the optimal breastfeeding practice.

In this study, mothers who did not attend formal education fed breast more non-exclusively than those who attended formal education. This finding was supported by studies done in Ethiopia $(13,45)$ and Nigeria $(11)$. However, the finding was inconsistent with the finding of a study conducted in Oromia Region, Bishoftu Town, in which mothers who did not attend formal school practiced exclusive breast feeding more likely than those who attended (25). This might be due to the difference in the study participants and the study setting.

Counseling on breastfeeding during ANC visits was significantly associated with non exclusive breast feeding. Mothers who were not counseled about breastfeeding during ANC visits were more likely to feed breast non-exclusively than mothers who were counseled. This finding is in line with findings of similar studies conducted in Addis Ababa public health centers, Debre Markos, Mecha District and Debre Berhan (17,18, $7,44)$. The possible explanation for this finding is the lower prevalence of postnatal care service. In the study setting, only (31.5\%) of the mothers had postnatal services.

Mothers with lower birth order (first born) were two times more likely to fed breast nonexclusively than mothers of higher birth order. This finding is consistent with the findings of studies conducted in Malaysia in which primiparous women were more likely not to exclusively breast feed than multiparous mothers
(47). Moreover, a literature review of the factors that influence breastfeeding showed similar finding (42). This might be related to the fact that mothers with lower birth order did not have the experience of breastfeeding as multiparous mothers.

Mothers' knowledge about exclusive breastfeeding is significantly associated with nonexclusive breastfeeding practice. Mothers who had no knowledge about exclusive breastfeeding were five times more likely to breastfed nonexclusively than their counterparts. This finding is in line with the finding of a similar study conducted in a rural community of east Ethiopia (43). Moreover, the finding of this study is consistent with the finding of a study conducted in Northwest Ethiopia, in which mothers having knowledge of complementary feeding time protected their infants from non-exclusive breastfeeding (10).

This study has some limitations. Firstly, as tudy was the cross-sectional study, the causeeffect relationship of different variables with delayed initiation of breast feeding and nonexclusive breast feeding could not be assessed. Secondly, maternal skills of breastfeeding practice (positioning and attachment) were not measured. Thirdly, socioeconomic status was assessed simply by asking monthly salary which would not be good to compute wealth index. Lastly, in order to generate more information from the study participants, it would have been good if qualitative data collection approaches were considered besides the quantitative one. However, recall bias was reduced through exclusion of mothers who had children above one year, and to identify study subjects, survey was conducted in the selected kebeles by using health promoters from each kebele.

Generally, this study revealed that the prevalence of sub-optimal breast feeding was high. Delayed initiation and non-exclusive breastfeeding practices were major contributors of sub-optimal breastfeeding. Very few numbers of mothers tend to introduce pre-lacteal foods and discarded colostrums. Not attending formal education, lack of breast feeding counseling,

DOI: http://dx.doi.org/10.4314/ejhs.v28i1.7 
lower number of ANC visits, having $<5$ family size and one under five year child were found to be predictors of delayed initiation of breast feeding. In addition, no maternal education, lower birth order, lack of breast feeding counseling during ANC visits and lack of knowledge about exclusive breastfeeding were found to be predictors of non-exclusive breast feeding practice.

Health extension workers should address the traditional and cultural belief relating to discarding colostrum, delayed initiation of breast feeding and non-exclusive breast feeding and create awareness on benefits of optimal breast feeding. Healthcare workers should counsel women about optimal breast feeding practice during ANC visits, delivery and postnatal care services. The district administration should give emphasis to increasing the formal education enrolment of women. The Federal Ministry of Health and nongovernmental organizations working on infant and young child feeding programs should focus on factors that cause delayed initiation of breast feeding and nonexclusive breast feeding practice.

\section{ACKNOWLEDGEMENTS}

We are grateful to Hawassa University for the technical and financial support. We would also like to thank the data collectors and the study participants.

\section{REFERENCES}

1. UNICEF. Breastfeeding is the cheapest and most effective life-saver in history. UNICEF Ethiopia and New York, 2013. Available at https://www.unicef.org/media/media

70044.html. [ Last accessed on 2017 April $10]$.

2. UNICEF. Breastfeeding: Impact on child survival and global situation. Available at https://www.unicef.org/nutrition/index_24824 .htm. [Last accessed on 2017 April 20].

3. World Health Organization, UNICEF. Global nutrition target 2025 breast feeding policy brief. Geneva: WHO/UNICEFI, 2014. Available http://www.who.int/nutrition/publications/glo baltargets. [Last accessed on 2017 January 5].

4. Ministry of Health Federal Democratic Republic of Ethiopia: Alive and thrive, Ethiopia. Infant and young child feeding quick reference book (0-24 months), 2010. Available at http://aliveandthrive.org/wpcontent/uploads/. [Last accessed on 2017 January 8].

5. UNICEF. Global Strategy on Infant and Young Child Feeding. Geneva: WHO; 2003. Available

\section{at} http://whqlibdoc.who.int/publications/2003/9 241562218.pdf. [Last accessed on January 20].

6. WHO, UNICEF. Global strategy for infant and young child feeding. Geneva: WHO; 2003. Available at http://www.who.int/nutrition/publications/infa ntfeeding/. [Last accessed on 2017 January 21].

7. Woldie T, Kassa A, Edris M. Assessment of exclusive breast feeding practice and associated factors in Mecha district, North west Ethiopia. Science Journal of Public Health 2014; 2:330-336.

8. Black R, Victora C, Walker S, Bhutta Z, Christian P, Onis M, et al. Maternal and child undernutrition and overweight in low-income and middle-income countries. lancent series 2013;382: 427-51.

DOI: http://dx.doi.org/10.4314/ejhs.v28i1.7 
9. Central Statistical Agency and ICF Macro. Ethiopia Demographic and Health Survey 2011 Central Statistical Agency Addis Ababa, Ethiopia; ICF Macro Calverton, Maryland,USA 2011.

10. Berhanu M, Zemene W, Mekonnen M. Prevalence and Associated Factors of Nonexclusive Breastfeeding to Infants within the First 6 Months in Gondar Town, Northwest Ethiopia, 2014. Hindawi, Advances in Nursing 2015; 1-7.

11. Ogbo F, Agho K, Page A. Determinants of suboptimal breastfeeding practices in Nigeria: evidence from the 2008 demographic and health survey. BMC Public Health 2015;15:259.

12. Alebachew F, Girma N, Tessema T. The Prevalence of Exclusive Breast Feeding and Associated Factors Among Mothers of Less than Two Years Children in Kurkur Kebele, Dessie Town. Pediatric and Adolescent Medicine 2016; 1(1): 7-15.

13. Setegn $T$, Gerbaba $M$, Belachew $T$. Determinants of timely initiation of breastfeeding among mothers in Goba Woreda, South East Ethiopia. BMC Public Health 2011;11:217.

14. Horii N, Guyon A, Quinn V. Determinants of delayed initiation of breastfeeding in rural Ethiopia. Food and Nutrition Bulletin, The United Nations University 2011;32(2):94-102.

15. Victor R, Baines S, Agho K, Dibley M. Determinants of breastfeeding indicators among children less than 24 months of age in Tanzania: a secondary analysis of the 2010 Tanzania Demographic and Health Survey. BMJ Open 2013;3(1):1-9.

16. Teka B, Assefa H, Haileslassie K. Prevalence and determinant factors of exclusive breastfeeding practices among mothers in Enderta woreda, Tigray, North Ethiopia: a cross-sectional study. Int Breastfeed $\mathrm{J}$ 2015;10 (1):1-7.

17. Shifraw T, Worku A, Berhane Y. Factors associated exclusive breastfeeding practices of urban women in Addis Ababa public health centers, Ethiopia: a cross sectional study. Int Breastfeed J 2015; 10(22):1-6.

18. Gultie1T, Sebsibie G. Determinants of suboptimal breastfeeding practice in Debre Berhan town, Ethiopia: a cross sectional study. Int Breastfeed J 2016; 11(5):1-8.

19. Tamiru D, Belachew T, Loha E, Mohammed S. Sub-optimal breastfeeding of infants during the first six months and associated factors in rural communities of Jimma Arjo Woreda, Southwest Ethiopia. BMCPublic Health 2012;12:363.

20. Bekele Y, Mengistie B, Mesfine F. Prelacteal Feeding Practice and Associated Factors among Mothers Attending Immunization Clinic in Harari Region Public Health Facilities, Eastern Ethiopia. Open Journal of Preventive Medicine, 2014, 4, 529-534.

21. Government of the Federal Democratic Republic of Ethiopia. National Nutrition Programme. Available at https://www.unicef.org/ethiopia/National_Nu trition_Programme. [Last accessed on 2017 February 10].

22. Tamiru D, Aragu D, Belachew T. Survey on the introduction of complementary foods to infants within the first six months and associated factors in rural communities of Jimma Arjo International Journal of Nutrition and Food Sciences 2013; 2:77-84.

23. Legesse M, Demena M, Mesfin F, Haile D. Prelacteal feeding practices and associated factors among mothers of children aged less than 24 months in Raya Kobo district, North Eastern Ethiopia. Int Breastfeed J 2014; 9: 189.

24. Legesse M, Demena M, Mesfin F, Haile D. Factors Associated with Colostrum Avoidance Among Mothers of Children Aged less than 24 Months in Raya Kobo district,North-eastern Ethiopia: Communitybased Cross-sectional study. Tropical pediatrics 2015:1-7.

25. Kebede Z. Determinants of Optimum Breastfeeding Among Mothers of Child Less than Two Years in Bishoftu Town, East Shewa Zone of Oromia Region, Ethiopia.

DOI: http://dx.doi.org/10.4314/ejhs.v28i1.7 
Science Journal of Public Health 2015; 3: 544-551.

26. Federal Ministry of Health Family Health Department, Ethiopia. National Strategy for Infant and Young Child Feeding, 2004. Available at https://extranet.who.int/nutrition/gina/sites /default/files/. [Last accessed on 2017 February 6]

27. World Health Organization. Infat and young child feeding: Model Chapter, 2009.Available at http://www.who.int/nutrition/publications/inf antfeeding/. [Lat accessed on 2017 February 5].

28. UNICEF. Breastfeeding on the world wide agenda, 2013. Available at https://www.unicef.org/eapro/breastfeeding on_worldwide_agenda.pdf. [Last accessed on 2017 February 15].

29. Assefa T, Samuel A, Argaw A, Selamawit N, Tekle A, Mesfin F, et al. Assessment of status of infant and young child feeding (IYCF) practice, policy and programs. Ethiopian Public Health Instution, 2013. Available at http://www.eldis.org/go/home\&id $=69742 \&$ ty pe=Document. [Last accessed on 2017 February 18].

30. Family Health Department, Fedral Ministry of Health. National Strategy for Child Survival in Ethiopia,2005, Addis Ababa, Ethiopia. Available https://extranet.who.int/nutrition/gina/site. [Last accessed on 2016 December 17].

31. Black R, Allen L, Bhutta Z, eld L, Onis M, Ezzati M, et al. Maternal and child undernutrition: global and regional exposures and health consequences. Lancent Series 2008; 371:243-60.

32. Hajeebhoy N, Nguyen P, Mannava P, Nguyen T, Mai L. Suboptimal breastfeeding practices are associated with infant illness in Vietnam. Int Breastfeed J 2014;9:1-12.

33. WHO, UNICEF. Breastfeeding advocacy initiative for the best start in life, 2015. Available at http://www.who.int/nutrition/publications/inf antfeeding/breastfeeding_advocacy_initiativ e/en/. [Last accessed on 2017 February 25].

34. Alive and Thrive. Creating a culture of optimal breastfeeding: an investment in Burkina Faso's health, social, and economic development, Canada:2015. Available at http://aliveandthrive.org/wp-

content/uploads. [Last accessed on 2017 February 17].

35. Cai X, Wardlaw T, Brown D. Global trends in exclusive breastfeeding. Int Breastfeed $\mathbf{J}$ 2012; 7(12):1-5.

36. Roberts T, Carnahan E, Gakidou E. Burden attributable to suboptimal breastfeeding: a crosscountry analysis of country-specific trends and their relation to child health inequalities. The lancet 2013; 381:126.

37. El-Gilany A, Abdel-Hady DM. Newborn First Feed and Prelacteal Feeds in Mansoura, Egypt. Hindawi 2014:7.

38. Anoshirike CO, Ejeogo CP, Nwosu C, Maduforo AN, Nnoka Kingsley O. Infant Feeding Practices Among Mothers and Their InfantsAttending Maternal And Child Health In Enugu, Nigeria. Journal of Biology, Agriculture and Healthcare 2014; 4(10):130139.

39. Tamiru D, Mohammed S. Maternal knowledge of optimal breastfeeding practices and associated factors in rural communities of Arba Minch Zuria. International Journal of Nutrition and Food Sciences 2013; 2: 122-129.

40. Hazir T, Akram D, Nisar Y, Kazmi N, Agho $\mathrm{K}$, Abbasi $\mathrm{S}$, et al. Determinants of suboptimal breast-feeding practices in Pakistan. Public Health Nutrition 2012;16(4): 659-672.

41. Central Statistical Agency and ORC Macro. Ethiopia Demographic and Health Survey 2005. Central Statistical Agency Addis Ababa, Ethiopia, ORC Macro Calverton, Maryland,USA: 2005.

42. Emmanuel A. A Literature Review of the Factors That Influence Breastfeeding: An Application of the Health Belief Model. International Journal of Nursing and Health Science 2015; 2: 28-36. 
43. Egata G, Berhane Y, Worku A. Predictors of non-exclusive breastfeeding at 6 months among rural mothers in east Ethiopia. Int Breastfeed J 2013; 8:8.

44. Mekuria G, Edris M. Exclusive breastfeeding and associated factors among mothers in Debre Markos, Northwest Ethiopia: a crosssectional study. Int Breastfeed J 2015;10:1.

45. Alemayehu $T$, Haidar J, Habte D. Determinants of exclusive breastfeeding practices in Ethiopia. Ethiop $J$ Health Dev $2009 ; 23: 12-18$.
46. Lauer J, Betrán A, Victora C, Onís M, Barros A. Breastfeeding patterns and exposure to suboptimal breastfeeding among children in developing countries. BMC Medicine 2004; $2: 26$.

47. Leong D. Factors Associated with Nonexclusive Breastfeeding among 4-Week Post-partum Mothers in Klang District, Peninsular Malaysia. Mal $J$ NFuatcrt 2009;15 (1): 11. 